\title{
ЕКСПЕРИМЕНТАЛЬНИЙ КОМПЛЕКС ДЛЯ ДОСЛІДЖЕННЯ ВПЛИВУ АУДІОСИГНАЛІВ НА ПСИХОМОТОРНІ ПОКАЗНИКИ
}

\author{
Берестюк K.P., студент \\ katusha.vredina@gmail.com \\ Овчаренко Г.P., ст. викл. каф. \\ ilikanet@ukr.net \\ Факультет біомедичної інженерії \\ Національний технічний університет \\ «Київський політехнічний інститут імені Ігоря Сікорського» \\ м. Київ, Україна
}

\begin{abstract}
Реферат - Одним з важливих показників працездатності є функиіональний стан ЦНС, на який суттєво впливають аудіостимули. Для аналізу цих впливів необхідно виділити у звуковому стимулі певні частотні діапазони та розробити оптимальний метод иьього впливу.

На основі попередніх досліджень було обрано частотний діапазон, щчо чинить значущий вплив на зміни електричної активності головного мозку. У відповідності до иього діапазону було підібрано 5 аудіостимулів. В результаті дослідження було проаналізовано вплив усіх обраних стимулів на зміну електричної активності головного мозку. В ході роботи було прийнято рішення про необхідність більш детального аналізу досліджуваного діапазону частот та розробки відповідної методики дослідження.

3 метою оцінки впливу звукових стимулів на функціональний стан ЦНС було розроблено програмно-апаратний комплекс. Для фільтрації аудіосигналів за заданими частотними діапазонами було використано програмне середовище MATLAB 2018. $3 a$ допомогою мови програмування С\# було розроблено програмне забезпечення для збору психомоторних показників функціонального стану ЦНС та моніторинг їх динаміки.
\end{abstract}

Ключові слова - програмно-апаратний комплекс, частотна характеристика, функціональний стан ЦНС, психомоторні показники, теппінг-тест, звуковий стимул, фільтрачія сигналу, діапазон частот, МАTLAB, С\#, шаv формат, маніпулятор мита, інтерфейс.

\section{I. ВСТУП}

Сучасні дослідження [1-5] свідчать про значний вплив звукових стимулів на діяльність ЦНС та зміни психофізіологічних показників організму людини. Було знайдено діапазон частот звукового стимулу, що чинять значущий вплив на зміни електричної активності головного мозку [6-8]. Однак цей діапазон складає більше 2 тисяч Гц, потребує звуження i виокремлення певних дієвих частот, для застосування їх у формуванні певної зміни функціонального стану.

Функціональний стан центральної нервової системи (далі - ЦНС) можна розглядати як інтегральний показник працездатності людини. Питання прогнозу, контролю та корекції функціонального стану людини мають велике теоретичне i практичне значення [9]. На сьогоднішній день існує багато методів його оцінки $[9,10]$, одним із них є теппінг-тест [11].

Однак існують дослідження, що не узгоджуються 3 класичним варіантом проведення тесту [12], що свідчить про необхідність удосконалення методики [13].

Таким чином важливо визначити які характеристики звукових стимулів та як саме впливають на функціональний стан ЦНС, а також об'єктивно оцінити реакцію головного мозку людини на зазначені характеристики.

\section{II. МЕТА ДОСЛІДЖЕННЯ}

Розробка програмно-апаратного комплексу для оцінки впливу звукових стимулів із заданими частотними характеристиками на функціональний стан ЦНС.

\section{III. МАТЕРІАЛИ І МЕТОДИ}

Для запису ЕЕГ використовувався програмно-апаратний комплекс «ЭкспертТМ» 
компанії Tredex - 16-ти канальний телеметричний електроенцефалограф.

Запис даних проводився при стандартній схемі розміщення електродів за міжнародною системою «10 - 20» [14], біполярна реєстрація відбувалася за допомогою 16 референтних електродів зі швидкістю $30 \mathrm{~mm} / \mathrm{c}$. Для дослідження використовувалися навушники «Panasonic RP-HJE118GU-K» та плеєр «iRiver T9 4GB».

В дослідженні використовувалося 5 музичних композицій 3 різними частотними характеристиками. Для аналізу спектрального складу аудіосигналів було використано швидке перетворення Фур'є [15]. Аналіз обраних звукових стимулів проводився за допомогою програмного пакету MATLAB 2018 [16].

Для програмної реалізації фільтрації звукового стимулу в заданому діапазоні частот, а також аналізу отриманих аудіостимулів було використано середовище MATLAB 2018.

\section{IV. РЕЗУЛЬТАТИ ТА ОБГОВОРЕННЯ}

На основі попередніх досліджень [6-8] було обрано частотний діапазон, що чинить значущий вплив на зміни електричної активності головного мозку, та підібрано 5 підходящих аудіостимулів.

У дослідженні використано формуючий стимул тривав загальною тривалістю 8 хв $21 \mathrm{c}$, який складався 35 аудіостимулів. Розпочинався він фоновою тишею, що тривала 2 хв, після чого відбувалося чергування треку та тридцяти секундної фонової тиші. Закінчувався формуючий стимул фоновою тишею, тривалістю 1,5 хв. Кожен 3 п'яти фрагментів музичних композицій було проаналізовано 3 допомогою середовища MATLAB 2018.

В якості аудіостимулів були використані мелодії, виконані на різних музичних інструментах, в яких переважає наявність середніх частот: кларнет (рис. 1, а), фортепіано (рис. 1, б), скрипка (рис. 1, в), фортепіано(рис. 1, г), труба (рис. 1, д).

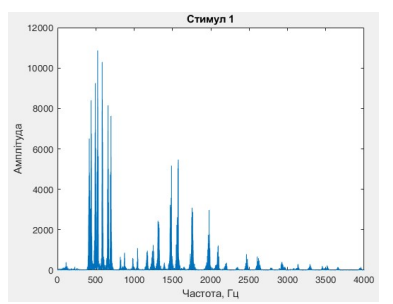

a)

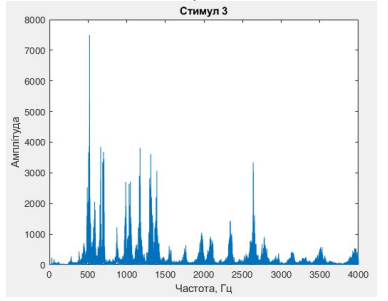

в)

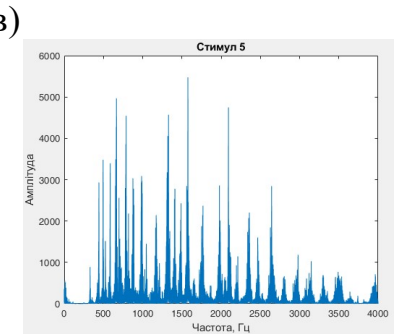

д)

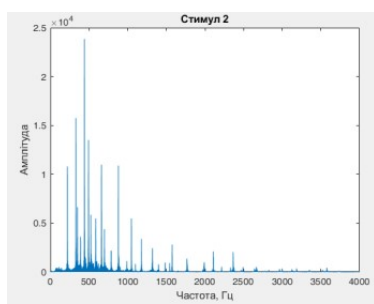

б)

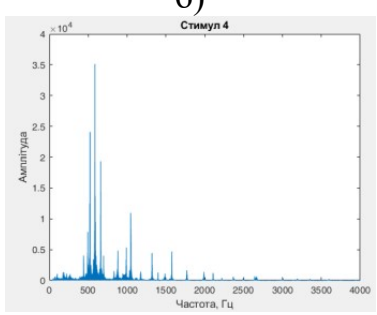

г)
Puc. 1 - Частотні характеристики досліджуваних стимулів: а) стимулу №1, б) стимулу №2, в) стимулу №3, г) стимулу №4, д) стимулу №5

В першому аудіостимулі наявні частоти від 450 до 2200 Гц, у другому - від 200 до 2400 Гц, у третьому - від 400 до 4000 Гц, у четвертому - від 500 до 1600 Гц, у п’ятому від 400 до 4000 Гц.

В ході роботи було досліджено вклади ритмів, узагальнені по кожному відрізку формуючого стимулу: під час прослуховування аудіосигналу та під час фонової тиші. Отримані значення по усіх досліджуваних були нормовані відносно початкового. Вклади ритмів початкової фонової тиші були прийняті за еталонні для подальшого порівняння змін вкладів ритмів протягом прослуховування композиції (рис. 23).

На рисунку 2 представлено зміни вкладів $\beta 2$ ритму у відповідь на стимули, на рисунку 3 - $\alpha$ ритму. В групі досліджуваних спостерігалась реакція на усі стимули: збільшився вклад $\beta 2$ ритму (рис. 2 , а) під час прослуховування першого стимулу у третього, четвертого та п'ятого досліджуваного на 0,275\%, 0,28\% та 0,215\% відповідно, а також при прослуховуванні другого стимулу - на $0,33 \%, \quad 0,68 \%$ та $0,47 \%$ для кожного 3 досліджуваних відповідно. У цій же групі 
спостерігається суттєве зниження вкладу $\alpha$ ритму (рис. 3 , а) при прослуховуванні:

- стимулу №1 на $0,41 \%$ для третього, $3,265 \%$ для четвертого та $1.84 \%$ для п'ятого досліджуваного;

- стимулу №3 на 0,7\%, 0,73\% та 3,57\% для кожного з досліджуваних відповідно;

- стимулу №5 на 4,76\% для третього, $0,685 \%$ для четвертого та $0,845 \%$ для п'ятого досліджуваного.

У іншій групі, спостерігалась реакція на перший, третій та четвертий стимули:

- збільшення вкладу $\beta 2$ ритму під час прослуховування першого стимулу (рис. 2, б) на $0,595 \%$ для другого, 0,275\% для третього та $0,28 \%$ для четвертого досліджуваного, при одночасному зменшенні вкладу $\alpha$ ритму (рис. 3, б) на $3,675 \%, 0,41 \%$ та 3,265\% для кожного 3 досліджуваних відповідно;

- зменшення вкладу $\alpha$ ритму при прослуховуванні третього стимулу (рис. 3, б) на $1,7 \%$ для другого, $0,7 \%$ для третього та 0,73\% для четвертого досліджуваного;

- зменшення вкладу $\beta 2$ ритму під час прослуховування четвертого стимулу (рис. 2, б) на 1,38\% для другого, $1,355 \%$ для третього та $0,935 \%$ для четвертого досліджуваного, при одночасному підвищенні вкладу $\alpha$ ритму (рис. 3, б) на 1,49\%, 3,76\% та 7,66\% відповідно.

У третій виділеній групі досліджуваних спостерігалась реакція на перший, третій та п'ятий стимули:

- при прослуховуванні першого стимулу відбувалося збільшення вкладу $\beta 2$ ритму (рис. 2 , в) на $0,595 \%$ для другого, 0,28\% для четвертого та $0,215 \%$ для п'ятого досліджуваного, при одночасному зменшенні вкладу $\alpha$ ритму (рис. 3 , в) на $3,675 \%, 3,265 \%$ та $1,84 \%$ для кожного 3 досліджуваних відповідно;

- при прослуховуванні третього стимулу спостерігалась аналогічно реакція, що й при першому стимулі: зменшення вкладу $\beta 2$ ритму (рис. 2, в) на 0,715\% для другого, 1,125\% для четвертого та $0,785 \%$ для п'ятого досліджуваного, при одночасному зниженні вкладу $\alpha$ ритму (рис. 3 , в) на $1,7 \%, 0,73 \%$ та $3,59 \%$ для кожного 3 досліджуваних відповідно;

- при прослуховуванні п'ятого стимулу відбувалося зменшення владу $\alpha$ ритму (рис. 3, в) на $0,905 \%$ для другого, $0,685 \%$ для четвертого та $0,845 \%$ для п'ятого досліджуваного.

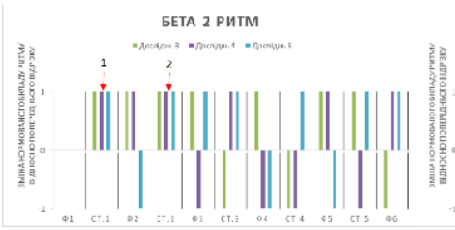

a)

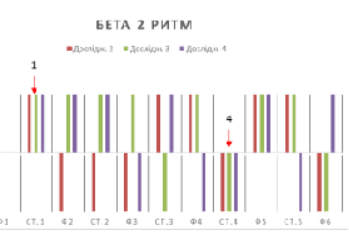

б)

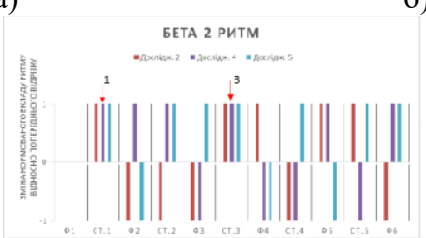

B)

Puc. 2 - Зміна вкладів $\beta 2$ ритму у відповідь на стимули: а) група досліджуваних $3,4,5$; б) група досліджуваних $2,3,4$; в) група досліджуваних 2, 4, 5

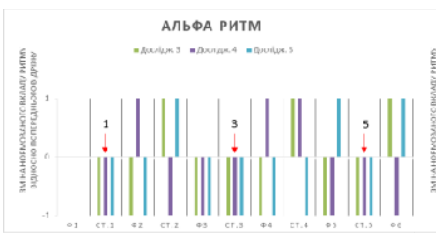

a)

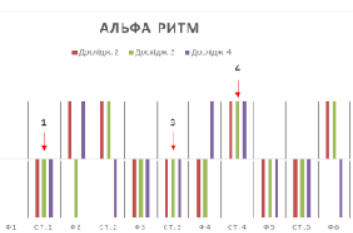

б)

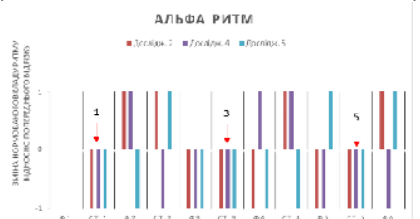

B)

Puc. 3 - Зміна вкладів $\alpha$ ритму у відповідь на стимули: а) група досліджуваних 3, 4, 5; б) група досліджуваних 2, 3,4 ; в) група досліджуваних 2, 4, 5

Результати аналізу свідчать про чітко виражену реакцію головного мозку людини на обрані стимули. Оскільки в даних композиціях переважають середні частоти, можна сказати про підтвердження результатів попередніх досліджень.

Після проведення дослідження, на основі отриманих даних було прийнято рішення про необхідність більш детального аналізу характеристик впливу i створення відповідного програмно-апаратного комплексу.

На рисунку 4 зображено структурну схему роботи програмно-апаратного комплексу. 


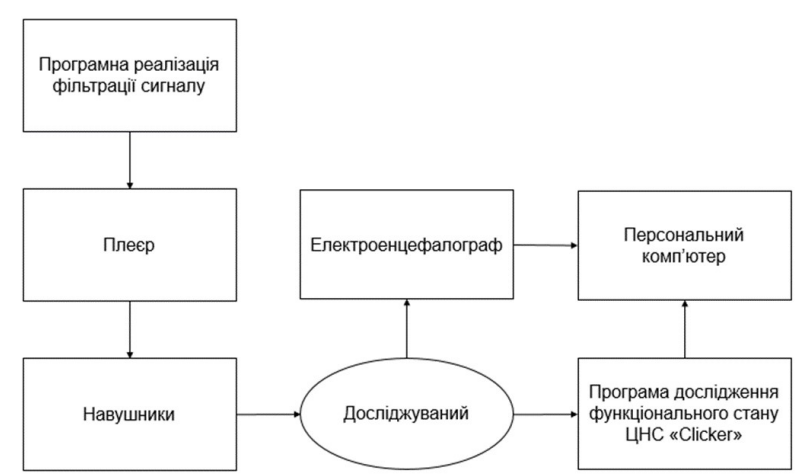

Puc. 4 - Структурна схема розробленого програмноапаратного комплексу

Розроблений

програмно-апаратний комплекс поділяється на 2 логічні елементи.

До першого елементу належить програмна реалізація фільтрації аудіостимулу, що була здійснена зі збереженням його вихідних характеристик, таких як тривалість сигналу, частота дискретизації та амплітуда.

В якості об'єкту для фільтрації було обрано частину відомого українського твору «Щедрик» у форматі wav. Частотні характеристики початкового сигналу представлені на рисунку 5.

Аналіз сигналу виявив наявність частот від 0 до 5 кГц. 3 попередніх досліджень [6-8] було визначено діапазон частот від 250 до 2998 Гц, що мають значущий вплив на електричну активність головного мозку людини. наявні у вихідному сигналі частоти повністю охоплюють цей діапазон, що дає можливість подальшого використання даного аудістимулу в роботі.

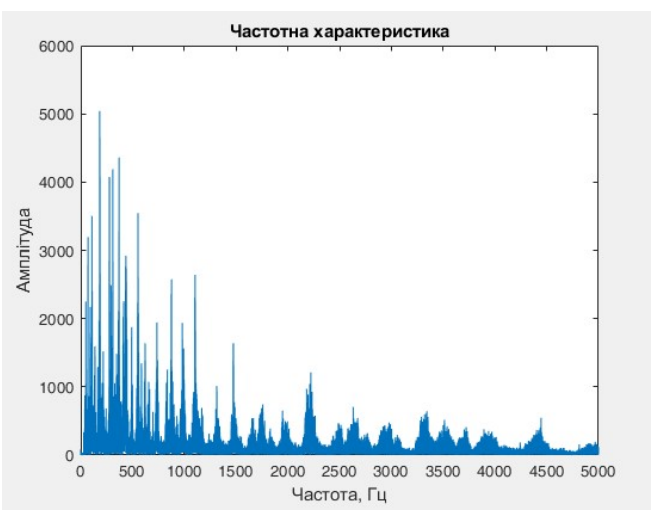

Puc. 5 - Частотна характеристика вихідного аудіостимулу

Визначений діапазон було довільно розділено на 5 частин 3 кроком 600 Гц (табл. 1) і створено відповідно 5 звукових доріжок.
Таблиця 1 - Частотні діапазони відфільтрованих звукових доріжок

\begin{tabular}{|l|l|}
\hline Відфільтровані стимули & Діапазон частот \\
\hline №1 & $260-760$ Гц \\
\hline №2 & $761-1260$ Гц \\
\hline №3 & $1261-1760$ Гц \\
\hline №4 & $1761-2260$ Гц \\
\hline №5 & $2261-2760$ Гц \\
\hline
\end{tabular}

При проектуванні реальних фільтрів було задано параметри «коридору амплітудночастотних характеристик» (далі - АЧХ) [18]. Граничні значення смуги пропускання були обрані відповідно до таблиці 1. Граничні значення смуги загородження були обрані 3 розрахунку \pm 10 Гц до значень смуги пропускання. Значення нерівномірності АЧХ в смузі пропускання вибрано мінімальним $(\mathrm{Rp}=$ 1 дБ), а значення послаблення в смузі загородження вибрано таким, що забезпечує найбільш оптимальне послаблення сигналу $(\mathrm{Rs}=150$ дБ).

Частотні характеристики відфільтрованих аудіостимулів представлені на рисунку 6 .

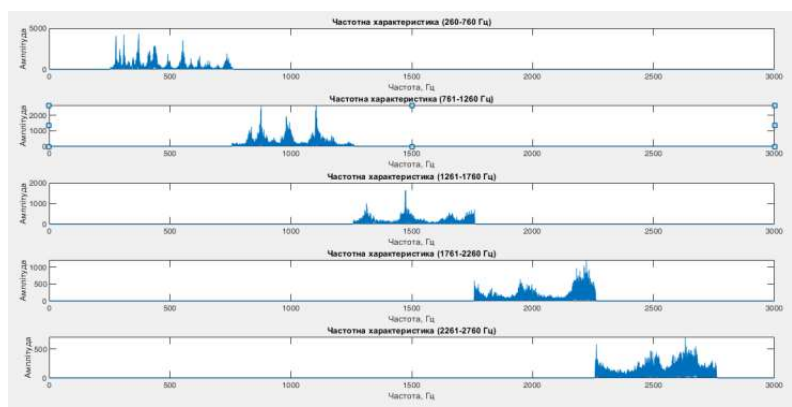

Puc. 6 - Частотні характеристики відфільтрованих сигналів

Відфільтровані аудіофайли були збережені як окремі доріжки у wav форматі.

До другого логічного елементу належить розробка методу оцінки функціонального стану ЦНС.

Після аналізу методів оцінки функціонального стану ЦНС у літературі, було обрано психомоторні показники як досліджуваний фактор. Для оцінки даного показника було обрано власну модифікацію теппінг-тесту Є. П. Ільїна [11]. Методика оцінки складається із підрахунку кількості натискань на маніпулятор миші протягом певного відрізку часу. Даний тест проводиться тричі 3 перервою в 1 хв між кожним тестуванням. Перерва між тестуваннями надавалася для запобігання 
накопичення м'язової втоми. Отримані результати нормувалися персонально для кожного досліджуваного та приймалися як еталонний діапазон значень оцінки функціонального стану ЦНС.

На рисунку 7 представлено алгоритм роботи розробленої програми.

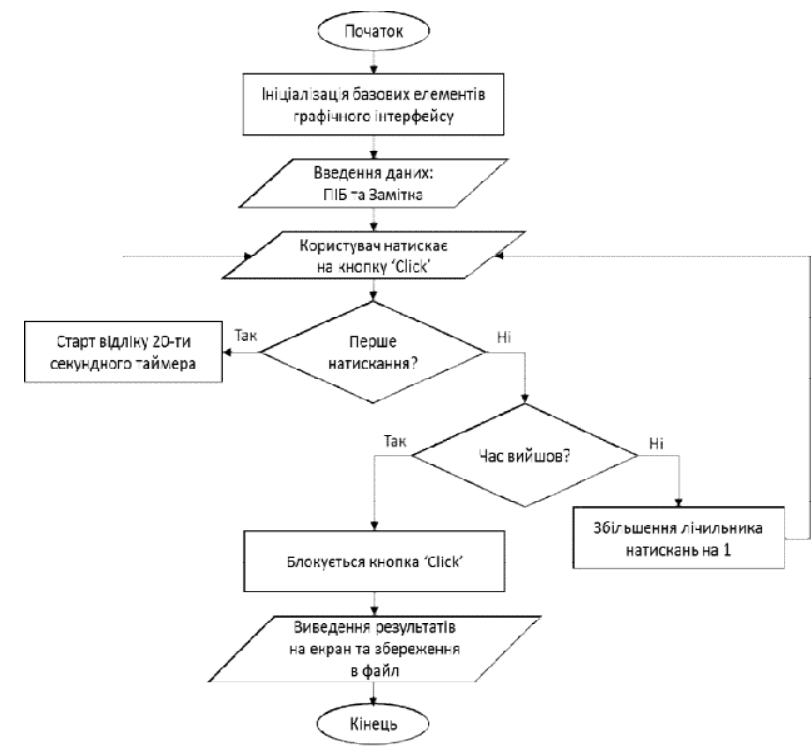

Puc. 7 - Алгоритм роботи програми «Clicker»

Розроблена програма надає можливість визначити психомоторні показники без застосування складних тестів чи громіздких розрахунків. Автоматизована методика проведення тестування дозволяю швидко отримати чіткі результати, що забезпечує якість дослідження.

На рисунку 8 представлена схема методики проведення тестування.

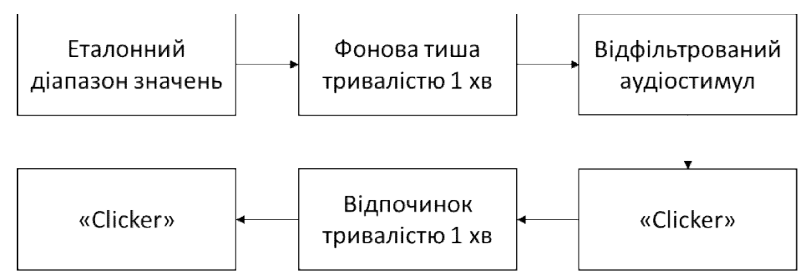

Puc. 8 - Методика проведення дослідження із застосуванням програмно-апаратного комплексу

Після проведення дослідження, в окремий файл зберігаються тестування (рис. 8, «Clicker») перед та після прослуховування аудіостимулів (рис. 6), що в подальшому порівнюються 3 еталонним діапазоном значень.

\section{V. ВИСНОВКИ}

1. Перевірено реакцію на частоти середнього діапазону.

2. Виявлено істотний вплив аудіо стимулів у діапазоні від 260 до 2760 Гц на динаміку вкладу $\alpha$ та $\beta 2$ ритмів.

3. Реалізовано програмну фільтрацію аудіо стимулів у заданому діапазоні частот.

4. Автоматизовано метод оцінки функціонального стану ЦНС на основі дослідження психомоторних показників за допомогою програми «Clicker».

5. Запропоновано методику використання експериментального програмноапаратного комплексу для дослідження впливу аудіо сигналів на функціональний стан ЦНС

\section{ПЕРЕЛІК ПОСИЛАНЬ}

[1] Гольдберг Е. М., Кривцунова А. Н., Пустовгар А. А. Влияние прослушивания музыки в наушниках на изменение частотного спектра ЭЭГ // Современные наукоемкие технологии. 2005. N4. С. 39-40.

[2] Близнюк О. А. Исследование применения метода определения базових эмоций на основе отношения частот спектра звуковой волны / О. А. Близнюк, А. П. Шкарапута. // Вестник Пермского университета. - 2017. C. 86-91.

[3] Розік А. I. Вплив музики на когерентність електроенцефалограми кори головного мозку в чоловіків та жінок під час виконання когнітивних завдань / [А. І. Розік, О. С. Павлович, Я. М. Чмух та ін.]. // Збірник наукових праць VIII Всеукраїнської науково-практичної конференції 3 міжнародною участю «Біологічні дослідження - 2017». - 2017.

[4] Шпєнков О. О. Зміни електричної активності головного мозку під час прослуховування рок-музики із видозміненною частотною структурою / О.О.Шпєнков, С. В. Тукаєв, І. Г. Зима, С. А. Крижановський // Вісник Черкаського університету. Серія «Біологічні науки». 2014. - № 2 (295). - C. 121-128. - ISSN 2076-5835.

[5] Павлович О. С. Індекс зміни потужності ЕЕГ в осіб із різним профілем асиметрії під час сприйняття та відтворення ритмічних звукових стимулів/ О. С. Павлович, А. Г. Моренко// Збірник наукових праць VIII «Біологічні дослідження - 2017». - 2017. - С.1-2.

[6] Дацок О. М. Вплив звукового сигналу на спектральні характеристики енцефалограми / О. М. Дацок, Г. Р. Овчаренко, К. О. Александрова, О. Р. Александров. // Інформаційні технології: наука, техніка, технологія, освіта, здоров'я: тези доповідей XXV міжнародної науково-практичної конференції MicroCAD-2018, 16-18 травня 2018p.: у 4 ч. Ч. III. / за ред. проф. Сокола Є.I. Харків: НТУ «ХПІ». С. 52.

[7] Александрова К. О. Методика дослідження впливу музичних фрагментів на показники електроенцефалограми / К. О. Александрова, Г. Р. Овчаренко, О. Р. Александров. // Сучасні напрями розвитку інформаційно-комунікаційних технологій та засобів управління: тези доповідей VIII міжнародної 
науково-технічної конференції, 26-27 квітня 2018p.: Харків: НТУ «ХПІ». С. 36.

[8] Калашнікова Л. Є. Зв'язок когнітивної діяльності 3 характеристиками $\beta$ - ритма під впливом аудіо стимулів різного компонентного складу. / Л. С. Калашнікова, Г. Р. Овчаренко, К. О. Александрова, О. Р. Александров. // Біомедична інженерія і технологія. 2018. №1. С. 130-135. ISSN (Print): 2617-8974.

[9] Шутова С. В. Сенсомоторные реакции как характеристика функціонального состояния ЦНС / С. В. Шутова, И. В. Муравьева. // Вестник ТГУ. - 2013. - С. 2831-2840. - ISSN 1810-0198.

[10] Бондарев Д. В. Особенности психофизических возможностей студентов, занимающихся спортивними играми / Д. В. Бондарев, В. А. Гальчинский. // Физическоевоспитаниестудентовтворческихспециальнос тей. - 2008. - С. 59-64. - ISSN 1993-4335.

[11] Веселова Н. Н. Теппинг-тест как інструмент педагогического изучения психофизиологических особенностей реализации студентами учебной деятельности / Н. Н. Веселова. // Среднее профессиональное образование. - 2007. - С. 75-76. ISSN 1990-679X.

[12] Никандров В.В. Психомоторика. Учебноепособие. СПб.: «Речь». 2004.c.79.

[13] Самороднов О. В. Теппинг-тест как індикатор включения релаксационного механизма срочной защиты [Електронний ресурс] / О. В. Самороднов, В. А. Чуев. [Веб-сайт]. - Електронні дані. - [ScientificWorld - 20102019].

Режим

доступу: https://www.sworld.com.ua/konfer27/380.pdf (дата звернення 15.05.2019). - Теппинг-тест как індикатор включения релаксационного механизма срочнойзащиты.

[14] Гусева Е.И., Неврология: национальноеруководство / Е.И. Гусева, А.Н. Коновалова, В.И. Скворцовой, А.Б. Гехт // ГЕОТАР-МЕДИА, 2010 - c.174 - 175.

[15] Дьяконов В. П. Современные методы Фурье-, вейвлет анали за сигналов. Контрольно-измерительные приборы и системы - 2009, № $2-25$ с.

[16] MATLAB [Електронний ресурс] : [Веб-сайт]. Електронні дані. - TheMathWorks, 1994-2019. - Режим доступу: https://www.mathworks.com/ (дата звернення 30.04.2019) - MATLAB forArtificialIntelligence.

[17] VisualStudioTeamServices [Електронний ресурс] : [Вебсайт]. - Електронні дані. - Microsoft - 2019. - Режим доступу:

https://visualstudio.microsoft.com/ru/?rr=https $\% 3 \mathrm{~A} \% 2 \mathrm{~F} \% 2 \mathrm{~F}$ msdn.microsoft.com\%2Fuk-ua (дата звернення 07.05.2019) - VisualStudio.

[18] Кафедра радіоконструювання та виробництва радіоапаратури [Електронний ресурс] : [Веб-сайт]. Електронні дані. - Кафедра КіВРА, 2019. - Режим доступу: http://kivra.kpi.ua/wpcontent/uploads/file/discipline/AOTI/AOTI_2_4-5.pdf (дата звернення 30.04.2019) - Фільтрація та передавання даних.

\title{
УДК 612.825
}

\section{ЭКСПЕРИМЕНТАЛЬНЫЙ КОМПЛЕКС ДЛЯ ИССЛЕДОВАНИЯ ВЛИЯНИЯ АУДИОСИГНАЛОВ НА ПСИХОМОТОРНЫЕ ПОКАЗАТЕЛИ}

\author{
Берестюк К.P., студент \\ katusha.vredina@gmail.com \\ Овчаренко A.P., ст. преп. каф. \\ ilikanet@ukr.net \\ Факультет биомедицинской инженерии \\ Национальный технический университет Украины \\ «Киевский политехнический институт имени Игоря Сикорского» \\ г. Киев, Украина
}

Реферат-Одним из важных показателей работоспособности является функииональное состояние ЦНС, на который существенно влияют аудиостимуль. Для анализа этих воздействий необходимо выделить в звуковом стимуле определенные частотные диапазоны и разработать оптимальный метод этого влияния.

На основе предыдущих исследований был выбран частотный диапазон, оказывающий значимое влияние на изменения электрической активности головного мозга. В соответствии с этим диапазоном было подобрано 5 аудиостимулов. В результате исследования было проанализировано влияние всех избранных стимулов на смену электрической активности головного мозга. В ходе работь было принято решение о необходимости более детального анализа исследуемого диапазона частот и разработки соответствующей методики исследования.

С иелью оценки влияния звуковых стимулов на функциональное состояние ЦНС был разработан программноаппаратный комплекс. Для фильтрачии аудиосигналов позаданным частотными диапазонами было использовано программную 
среду МАТLAB 2018. С помощью языка программирования С\# было разработано программное обеспечение для сбора психомоторных показателей функиионального состояния ЦНС и отслеживания их динамики.

Ключевые слова - программно-аппаратный комплекс, частотная характеристика, функциональное состояние ЦНС, психомоторные показатели, теппинг-тест, звуковой стимул, фильтрация сигнала, диапазон частот, MATLAB, C\#, wav формат, манипулятор мышь, интерфейс.

UDC 612.825

\title{
EXPERIMENTAL COMPLEX TO RESEARCH AUDIO SIGNALS INFLUENCE ON PSYCHOMOTOR INDICES
}

\author{
Berestiuk K.R., student \\ katusha.vredina@gmail.com \\ Ovcharenko G.R., Assoc.Prof. \\ ilikanet@ukr.net \\ FacultyofBiomedicalEngineering \\ NationalTechnicalUniversity \\ " Igor Sikorsky Kyiv Polytechnic Institute " \\ Kyiv, Ukraine
}

\begin{abstract}
One of the important indicators of health is the functional state of the CNS, which is significantly affected by audio stimuli. To analyze these effects, it is necessary to allocate certain frequency ranges in the sound stimulus and develop an optimal method for this influence.

Based on previous studies, the frequency range was chosen, having a significant impact on changes in the electrical activity of the brain, and 5 corresponding audio stimuli were selected. As a result of the study, the influence of all selected stimuli on the change in the electrical activity of the brain was analyzed. In the course of the work, a decision was made on the need for a more detailed analysis of the studied frequency range and the development of an appropriate research methodology.

In order to assess the impact of sound stimuli on the functional state of the central nervous system, a software and hardware complex was developed. The software environment MATLAB 2018 was used for filtering audio signals by specified frequency ranges. Using the C \# programming language, the software for collection psychomotor indicators of the functional state of the central nervous system and track their dynamics was developed.
\end{abstract}

Key words - software-hardware complex, frequency response, functional state of the CNS, psychomotor characteristics, tepping test, sound stimulus, signal filtering, frequency range, MATLAB, C\#, wav format, mouse manipulator, interface. 